\title{
Oil Spill Clean-up from Sea Water using Waste Chicken Feathers
}

\author{
[Augustine Osamor Ifelebuegu and Precious Chinonyere]
}

\begin{abstract}
Oil spill is a major environmental disaster that has continued to plague the petroleum industry. After the 2010 Deepwater Horizon spill, there has been an increase in research on the uses of low cost environmentally sustainable options for spill clean-up. The use of low-cost sorbents is considered a cost-effective and environmentally friendly. With over 5 million tonnes of waste chicken feathers generated annually around the globe, the management of the solid waste is an enormous challenge. In this paper, we examine the adsorptive removal of different oil types from sea water using waste chicken feathers. The adsorption properties were investigated in batch adsorption experiments using crude oil, vegetable oil and diesel fuel. The maximum adsorption capacities were $7694 \mathrm{mg} / \mathrm{g}, 6059 \mathrm{mg} / \mathrm{g}$ and 4097 $\mathrm{mg} / \mathrm{g}$ for vegetable oil, crude oil, and diesel fuel respectively. The adsorption kinetics varied inversely with increasing temperatures and was better described by the pseudo-second-order kinetic model.
\end{abstract}

\section{Keywords—oil, oil spills, sorption, chicken feathers}

\section{Introduction}

Crude oil exploration and production is a major aspect of the global economy because of the enormous revenues generated from its activities. Nonetheless, despite the many benefits emanating from the industry, the negative impacts that the exploration and production process can exert on the environment remains a major concern for the industry. Oil spill is one of the known sources of direct and indirect marine pollution. Although oil spills account for about 5 to 12 percent of oil contaminations, the high oil concentration deposited could cause great damage to affected areas. Oil spills can occur as a result of explosions, during transfer, accidents due to a collision, or leakages from pipelines or vessels $[1,2]$.

Oil spill recovery after a spill is usually challenging, costly and often a difficult task. Various methods are applied in the clean-up process including chemical, physical and biological methods. Use of sorbents is one of the physical methods and has been applied in the industry for several years. Commercial sorbents are extensively used in oil spill cleanup. The most commonly applied are synthetic sorbents like polystyrene, polypropylene, and polyester foams. They have high hydrophobic and oleophilic properties and can sorb up to 70 times their weight in oil. They can also be used several times after recovery in some instances [3].

Augustine Osamor Ifelebuegu, Precious Chinonyere

School of Energy, Construction and Environment, Coventry University United Kingdom
These conventional sorbents used in the process of cleaning oil spills are expensive and usually non-biodegradable and hence not environmentally sustainable. Low-cost nonconventional sorbents are emerging as alternatives to conventional materials used in oil-spill clean-up owing to their eco-friendliness, availability, and low cost. The use of agricultural and human wastes and by-products from industries has gained more attention since the Deep Water Horizon Disaster [4, 5]. A large arrays of naturally occurring materials have been investigated as potential sorbents for oil spill clean-up. These include cotton fibre, kapok, raw jute, rice husk and melon carbon aerogel [5], human hair and coconut coir [4]. They have the advantage of being inexpensive, readily available and usually biodegradable.

Over 5 million tonnes of chicken feathers (CFs) wastes are generated annually from commercial poultry farms around the World, creating an enormous and costly solid waste management change. In this paper, we investigate the potential application of waste CFs as sorbents for oil spill clean-up.

\section{Materials and Method}

\section{A. Materials}

The waste CFs used in this experiment were acquired from a local West Midlands poultry farm. The CFs were soaked for 24 hours and washed with bleach to remove odour. The hard rachis was removed from the shaft using scissors while the soft barbs were washed and oven dried. The CFs were further soaked with sodium bicarbonate and dried in an oven set at $140^{\circ} \mathrm{C}$ for 24 hours. The dried samples were pulverised to increase surface area. The cross sections of the sample were examined using a JOEL 6060LV model scanning electron microscope, Japan. The crude oil sample was Bonny Light crude. The vegetable oil was purchased from Sainsbury Supermarket, UK. The diesel fuel was purchased from Esso, Coventry, UK. Artificial sea water was prepared as has been previously described by Kester et al., [6].

\section{B. Batch Adsorption Studies}

Adsorption experiments were conducted in seawater as has been previously described by Ifelebuegu et al., [4]. Oil sorption capacities $(\mathrm{mg} / \mathrm{g})$ were obtained from equation 1 :

Sorption Capacity $=\frac{X_{o}-X_{S}}{X_{S}}$

Where $X_{o}$ is the total mass of wet sorbent after oil adsorption and $\mathrm{X}_{\mathrm{s}}$ is the mass of the adsorbent before adsorption. All experiments were conducted at room temperature $\left(25^{\circ} \mathrm{C} \pm 2^{\circ} \mathrm{C}\right)$ and carried out in triplicate with the average value and standard deviation (SD) calculated. 
Sample data with SD greater than $10 \%$ were rejected with a re-run of the test carried out.

\section{Results and Discussion}

\section{A. Surface Morphology}

The surface morphology of $\mathrm{CF}$ was characterised by using SEM analysis to determine the porosity and texture of the sorbent. According to Figure 1, chicken feathers have hollow structures of knots and hooks [7]. These hollow structures contribute to the available pore spaces for binding with the oil adsorbates. Entangled pore structure and rough morphology of sorbents materials are known to enhance oil retention [8].

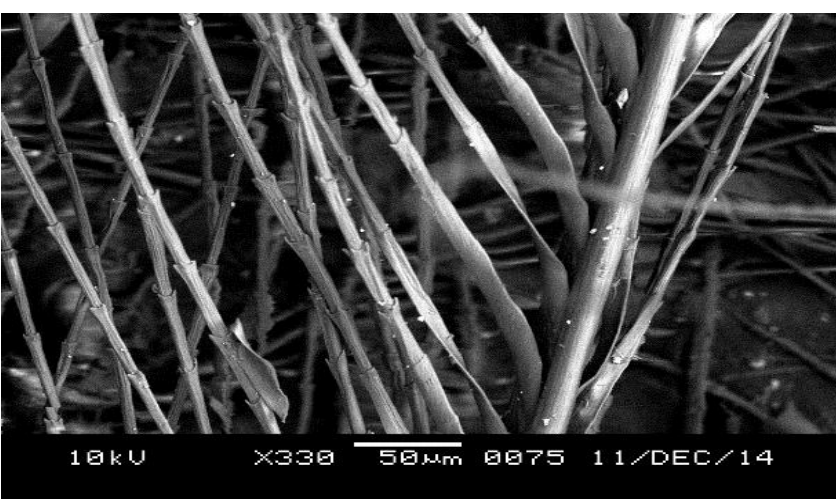

(a)

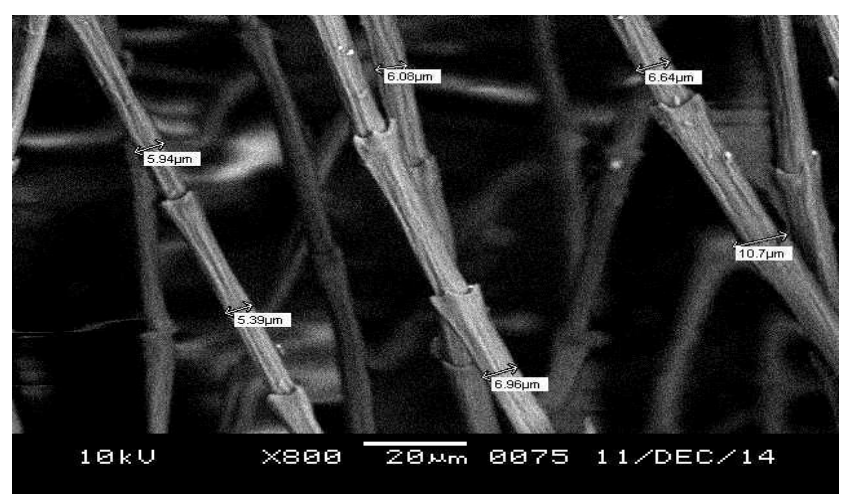

(b)

Figure 1a and b: SEM images of chicken-feather: $X 330$ and X800 magnification, $50 \mu \mathrm{m}$ and $20 \mu \mathrm{m}$ bar length equivalent, $10 \mathrm{KV}$ working voltage.

\section{B. Effect of Contact Time and Sorption Capacities}

The effects of contact time on oil sorption by chicken feathers for the three oil types are illustrated in Figure 2. It can be seen that the oil sorption process was rapid initially in the first 10 minutes, reaching equilibrium in about 30 minutes. The observed initial rapid sorption may be due to the movement of oil molecules from the higher concentration regions to the surface of the adsorbent. This result is similar to the trend observed by Ifelebuegu and Momoh [9] while using coconut coir to remove vegetable oil and diesel fuel from salt water. The high rate of sorption of the oils onto CF may be due to the high keratin contents and strong disulphide bonding which is mainly responsible for their hydrophobic characteristics. It can also be attributed to the hollow structures of knots and hooks as shown in figure 1.

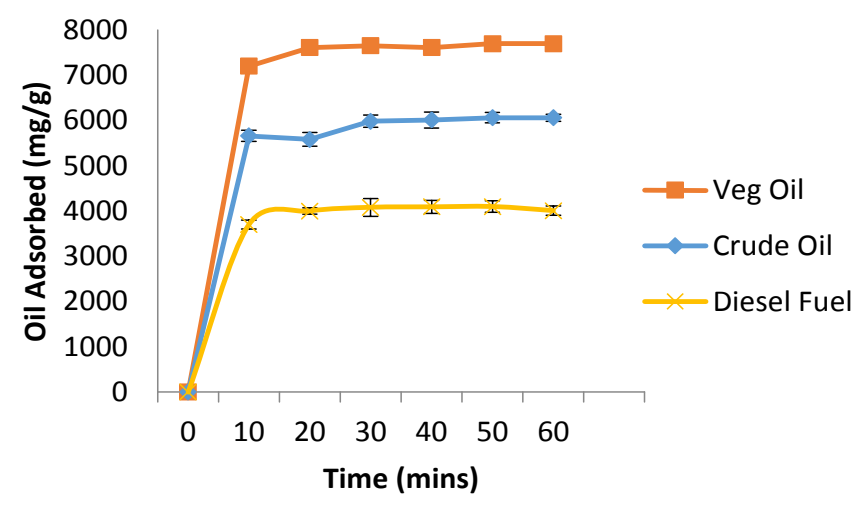

Figure 2. Adsorption Rate of $\mathrm{CF}$ in vegetable oil, crude oil and diesel fuel at temperature $25 \pm 2{ }^{\circ} \mathrm{C}$. The bars represent the standard deviation of the mean.

It can be seen that the sorption capacity for vegetable oil was the highest followed by crude oil and then diesel fuel. Similar results were reported by Ifelebuegu et al., [4], for the sorption of the same oils on human hair. The higher adsorption capacity for vegetable oil and crude oil are attributed to their higher viscosities, causing them to bind with the active sites on the CFs.

\section{Sorption Kinetics}

The adsorption kinetics was investigated for CF by using the pseudo-first order and pseudo-second order adsorption models as proposed by Lagergren, 1898 [10] and can be expressed linearly as equations 2 and 3 :

$$
\log \left(\mathrm{C}_{\mathrm{e}}-\mathrm{C}_{\mathrm{t}}\right)=\log \mathrm{C}_{\mathrm{e}}-\underline{\mathrm{k}}_{\underline{1}}
$$$$
\mathrm{t} / \mathrm{C}_{\mathrm{t}}=1 / \mathrm{k}_{2} * \mathrm{C}^{2}+\mathrm{t} / \mathrm{C}_{\mathrm{e}}
$$

Pseudo-first order plot of $\log (\mathrm{Ce}-\mathrm{Ct})$ against $\mathrm{t}$ should give a linear relationship from which $\mathrm{k}_{1}$ in $\left(\mathrm{min}^{-1}\right)$ can be calculated from the slope of the graph. A plot of $t / C_{t}$ will give a rate constant $\mathrm{k}_{2}\left(\mathrm{mg} \mathrm{g}^{-1} \mathrm{~min}^{-1}\right)$ for pseudo-second order kinetics. Table 1 present the constant values and correlation coefficients $\mathrm{R}^{2}$ of both pseudo-first order and pseudosecond-order kinetic models for adsorption of vegetable oil and diesel fuel onto CF. The pseudo second order model indicates that the adsorption process favours chemisorption. This implies that the oil molecules form strong bonds with active sites of CF [11]. Ifelebuegu et al, [4] and Ifelebuegu and Momoh [9] both reported a pseudo second order 
kinetics for the oil sorption onto human hair and coconut coir respectively.

Table 2. Results obtained from pseudo-first-order and pseudo second order kinetic modelling of the adsorption of vegetable oil and diesel fuel to $C F$.

\begin{tabular}{|l|l|l|l|l|}
\hline \multirow{2}{*}{ Oil Type } & \multicolumn{2}{|l|}{ Pseudo-first order } & \multicolumn{2}{c|}{ Pseudo-second order } \\
\cline { 2 - 5 } & $\mathrm{k}_{1}\left(\mathrm{~min}^{-1}\right)$ & $\mathrm{R}^{2}$ & $\begin{array}{c}\mathrm{k}_{2}\left(\mathrm{mg} \mathrm{g}^{-}\right. \\
\left.\mathrm{min}^{-1}\right)\end{array}$ & $\mathrm{R}^{2}$ \\
\hline Vegetable oil & 0.117 & 0.778 & 0.375 & 0.982 \\
\hline Diesel & 0.111 & 0.788 & 0.250 & 0.973 \\
\hline
\end{tabular}

\section{Effects of Temperatures}

The adsorption capacity of $\mathrm{CF}$ was investigated at varying temperatures $\left(18,25,30\right.$ and $\left.40^{\circ} \mathrm{C}\right)$. The results shown in Figure 3 demonstrated a decrease in adsorption capacity with increasing temperatures. The decrease can be attributed to increased water solubility and decreased viscosity with increasing temperatures $[4,9]$. The reduced viscosity causes an in increase in the binding energy of the CF to the oils due to increased Brownian motion $[12,13]$.

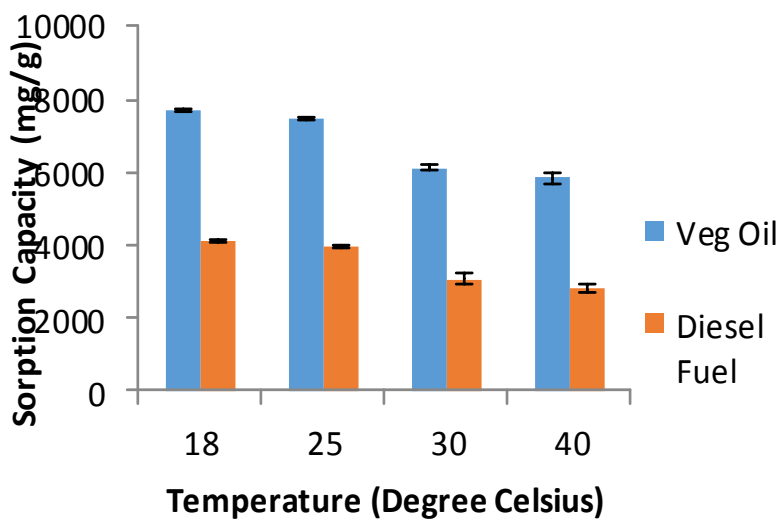

Figure 3. Effect of temperature on the sorption capacity of $\mathrm{CF}$ for vegetable oil and diesel fuel. The bars represent the standard deviation of the mean.

\section{Conclusion}

Waste chicken feathers were evaluated for their potential applicability as oil spill sorbents in batch experiments. Maximum sorption capacities of $7694 \mathrm{mg} / \mathrm{g}, 6059 \mathrm{mg} / \mathrm{g}$ and $4097 \mathrm{mg} / \mathrm{g}$ were achieved for vegetable oil, crude oil and diesel fuel respectively. The sorption capacities decreased with increasing temperature due to lower viscosity and increased Brownian motion at the oil sorbent interface. The adsorption kinetic followed a pseudo-second-order kinetic model with chemisorption as the rate determining step.

\section{References}

[1] S. Huisman, "Oil Spills: Effects and Management'. Marine Incidents Management Cluster (MIMAC) Research in the Framework of the BELSPO Supporting Actions SPSD II, 2006.

[2] International Tanker Owners Pollution Federation (2013) 'The Oil Tankers Spill Statistics' [online] available from <http://www.itopf.com/knowledgeresources/data-statistics/statistics/>

[3] A. K. Aboul-Gheit, F. H. Khalil, and T. AbdelMoghny, "Adsorption of spilled oil from seawater by waste plastic." Oil \& Gas Science and Technology 61(2), 259-268, 2006

[4] A.O. Ifelebuegu, T.V.A. Nguyen, P. Ukotije-Ikwut, and Z. Momoh, "Liquid-phase sorption characteristics of human hair as a natural oil spill sorbent." Journal of Environmental Chemical Engineering, 3(2), 938-943, 2015.

[5] E. Nyankson, D. Rodene, and R.B. Gupta, "Advancements in crude oil spill remediation research after the Deepwater Horizon Oil Spill. Water, Air, \& Soil Pollution, 227(1), 1-22, 2016.

[6] D.R. Kester, I.W. Duedall, D.N. Connors, R.M. Pytkowicz, Preparation of artificial seawater". J. Limnol. Oceanogr. 12, 176-179, 1967.

[7] D. D. Belarmino, R. Ladchumananandasivam, L. D. Belarmino, J. R. Pimentel, B. G. da Rocha, A. O. Galvão,and S. M. de Andrade, "Physical and morphological structure of chicken-feathers (Keratin Biofiber) in natural, chemically and thermally Modified forms'. Materials Sciences and Applications 3, 887, 2012.

[8] R. Wahi, L.A. Chuah, T.S.Y. Choong, Z. Ngaini, and M.M. Nourouzi, "Oil removal from aqueous state by natural fibrous sorbent: an overview." Separation and Purification Technology, 113, pp.51-63, 2013

[9] A.O. Ifelebuegu, and Z. Momoh, "An evaluation of theadsorptive properties of coconut husk for oil spill cleanup," Proceedings of the International Conference on Advances in Applied Science and Environmental Technology - ASET 2015, Bangkok, Thailand, 21-22 February 2015.

[10] S. Langergren, and K. Svenska, "About the theory of so-called adsorption of soluble substances," Kungliga Svenska Vetenskapsakademiens Handlingar, vo. 24 pp. $1-39,1898$.

[11] M. A. Khosa, J. Wu, and A. Ullah, "Chemical modification, characterization, and application of chicken-feathers as novel biosorbents'. Rsc Advances 3 (43), 20800-20810, 2013. 
[12] K. Amela, M. A. Hassen, and D. Kerroum, "Isotherm and kinetics study of biosorption of cationic dye onto banana peel," Energy Procedia, vol. 19, pp. 286-295, 2012.

[13] I. A. Okoro, D. Okwu and U. Emeka, "Sorption Kinetics and intra particulate diffusivity of crude oil on kenaf (Hibiscus Cannabinus L.) plant part," Journal of Engineering and Applied Science, vol. 2, pp. 170-173, 2007. 